\title{
苯酚与烯烃的氧化环加成反应研究进展
}

\author{
崔 娜赵 宇王云侠* \\ (西北大学合成与天然功能分子化学教育部重点实验室 化学与材料科学学院 西安 710127)
}

\begin{abstract}
摘要 苯酚的氧化和随后丰富的化学转化可以构筑多种生物活性分子的核心骨架, 其中苯酚与烯烃氧化环加成反应的 产物一二氢苯并呋喃广泛存在于新木脂素和白僽芦醇低聚物等活性天然产物结构当中, 因此苯酚与烯烃的氧化环加成 反应受到了有机化学家的广泛关注. 根据反应条件的不同, 对近年来苯酚与烯烃的氧化环加成反应进行了分类与综述, 并对相应的机理进行了讨论.

关键词 苯酚; 烯烃; 氧化环加成反应; 二氢苯并呋喃
\end{abstract}

\section{Recent Advances in Oxidative Cycloaddition Reactions of Phenols with Olefins}

\author{
Cui, Na Zhao, Yu Wang, Yunxia* \\ (Key Laboratory of Synthetic and Natural Functional Molecule Chemistry of Ministry of Education, School of Chemistry \& \\ Material Science, Northwest University, Xi'an 710127)
}

\begin{abstract}
Phenol oxidation and the induced transformations can construct various core skeletons of bioactive molecules. Due to the extensive existence of dihydrobenzofuran core, which could be generated from the oxidative cycloaddtion reaction of phenols and olefins in bioactive neolignans and resveratrol oligomers, the oxidative cycloaddition reaction of phenols and olefins catched broad attention from organic chemists. Herein, the progress of oxidative cycloadditon reactions of phenols and olefins in recent years is reviewed according to the difference of reaction conditions, and the corresponding reaction mechanisms are discussed.
\end{abstract}

Keywords phenol; olefin; oxidative cycloaddition reaction; dihydrobenzofuran

苯酚的氧化和随后丰富的化学转换可以实现多种 有机结构骨架的构建，例如苯酚氧化去芳香性以及随后 的亲核加成反应广泛用于一些复杂有机化合物的合 成 ${ }^{[1]}$ 苯酚自身氧化偶联反应可以构建联苯类化合物 ${ }^{[2]}$, 苯酚与烯烃、炔烃 ${ }^{[3]} 、 \beta$-酮酸酯 ${ }^{[4]}$ 、吲哚 ${ }^{[5]} 、 2$-氨基苯乙

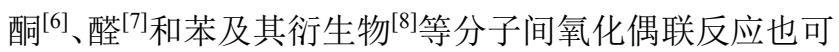
以构建结构多样的杂环结构, 其中苯酚与烯烃的氧化环 加成反应构建的二氢苯并呋喃骨架存在于多种生物活 性分子中，例如一些生物活性的新木脂素和白藜芦醇低 聚物结构中, 都含有二氢苯并呋喃核心骨架 ${ }^{[9]}$ (图 1), 因 此苯酚与烯烃的氧化环加成反应受到有机化学家的广 泛关注. 本文主要根据反应条件的不同, 将苯酚与烯烃 的氧化环加成反应进行了分类与综述, 并对相应的反应 机理进行了讨论.

\section{1 催化的氧化环加成反应}

\section{1 铁盐催化}

2013 年 $\mathrm{Lei}$ 等 ${ }^{[10]}$ 报道了 $\mathrm{FeCl}_{3}$ 催化的苯酚与烯烃的 氧化自由基交叉偶联环化反应(Scheme 1). 该研究首先 以对甲氧基苯酚和 $\alpha$-甲基苯乙烯为模板化合物, $\mathrm{FeCl}_{3}$ 为催化剂, 2,3-二氯-5,6-二氰基-1,4-苯醌(DDQ)为氧化 剂, 甲苯为溶剂, 室温条件下实现了苯酚和烯烃的氧化 交叉偶联/环化反应，得到了相应的二氢苯并呋喃类化 合物. 在底物拓展研究中发现, 该反应可以高效率、高 选择性地实现对甲氧基苯酚、䒺酚等酚类和 $\alpha$-烷基苯乙 烯、䒺取代的乙烯等烯烃的氧化环加成反应. 2014 年,

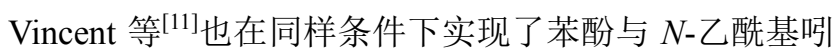
哚的氧化偶联反应, 构建了苯并呋喃并吲哚啉核心骨

\footnotetext{
* Corresponding author. E-mail: wyx27210@nwu.edu.cn

Received July 10, 2016; revised August 30, 2016; published online September 8, 2016.

Project supported by the National Natural Science Foundation of Shaanxi Province (No. 2011JQ2001).

陕西省自然科学基金(No. 2011JQ2001)资助项目.
} 


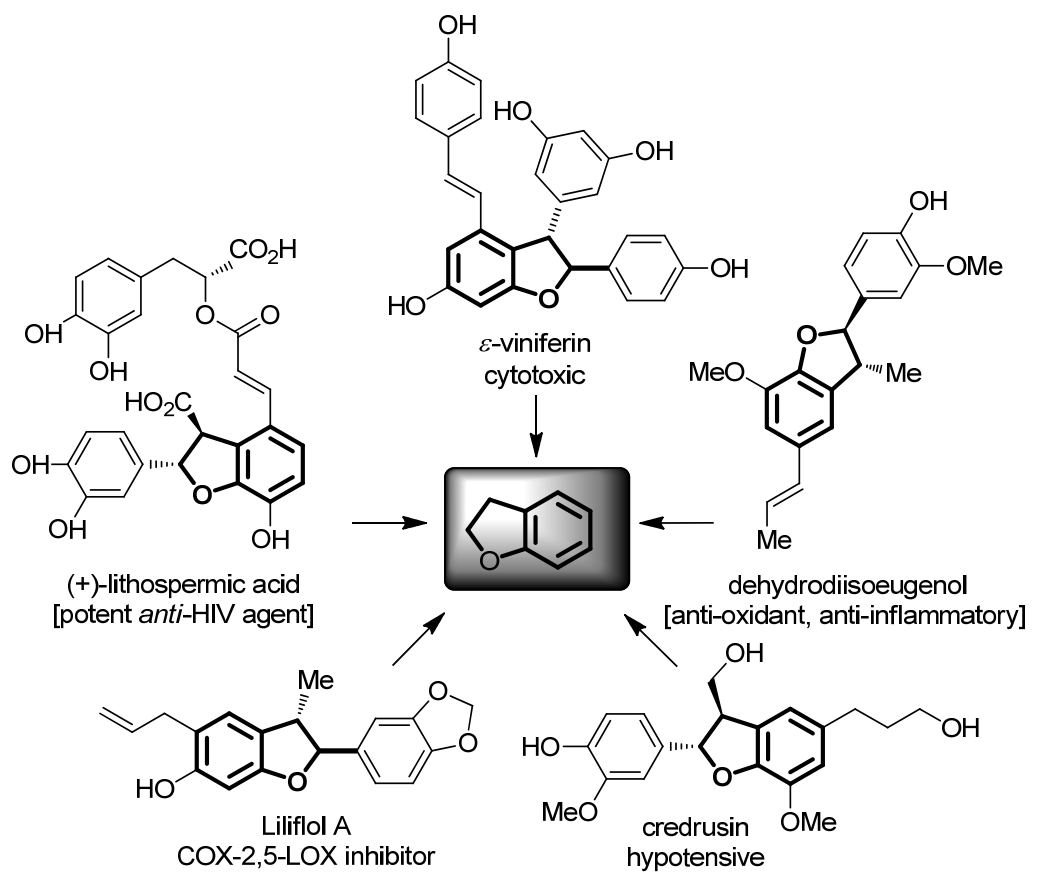

图 1 一些含有二氢苯并呋喃核心骨架的新木脂素和白愁芦醇低聚物

Figure 1 Some neolignans and resveratrol oligomers featured with dihydrobenzofuran core

架. 2016 年, Xia 等 ${ }^{[12]}$ 也将该方法应用到 5-羟基吲哚与苯 乙烯及其衍生物或肉桂酸衍生物的氧化自由基偶联反 应, 构建了吲哚呋喃核心骨架及相关的活性天然产物.

Lei 课题组 ${ }^{[10]}$ 通过 2,2,6,6-四甲基哌啶氧化物 (TEMPO)自由基捕捉实验、电子顺磁共振(EPR)实验和 原位红外实验等对该反应机理进行研究, 推测反应可能 的机理如 Scheme 1 所示: 首先 DDQ 氧化苯酚, 产生苯 酚氧自由基 1 和 HDDQ, 接着 $\mathrm{FeCl}_{3}$ 作为路易斯酸促使 $\mathbf{1}$ 转化为碳自由基 $\mathbf{2}$, 接着 $\mathbf{2}$ 再与烯烃发生自由基加成反 应形成自由基中间体 $\mathbf{3}$, 最后 HDDQ. 提取中间体 $\mathbf{3}$ 中的 氢自由基, 从而生成目标产物二氢苯并呋喃类化合物. 作者认为在该反应过程中, $\mathrm{FeCl}_{3}$ 稳定了自由基 $\mathbf{2}$, 并提 高了 2 的反应活性, 从而高选择性地形成了目标化合物 二氢苯并呋喃, 反应也未检测到酚氧自由基 $\mathbf{1}$ 与烯烃发 生自由基加成反应的产物.

2013 年 Pappo 等 ${ }^{[13]}$ 报道了 $\mathrm{FeCl}_{3} \cdot\left(\mathrm{H}_{2} \mathrm{O}\right)_{6}$ 为催化剂, 二叔丁基过氧化物(DTBP)为氧化剂, 苯酚与共轭烯烃 在二氯甲烷的稀溶液中的氧化环加成反应, 为二氢苯并 呋喃提供了一种新的合成策略(Scheme 2). 该方法适用 于富电子的苯酚或䒺酚与苯乙烯、 $\alpha$-烷基取代的苯乙 烯、 $\alpha$-芳基取代的苯乙烯、 $\beta$-烷基取代的苯乙烯及二苯 代乙烯类化合物的氧化环加成反应. 研究发现, 该反应 对铁源和反应浓度都很敏感, 当用 $\mathrm{FeCl}_{2}$ 作催化剂, 反 应物浓度较高时, 荥酚发生自身偶联反应生成 1,1'-联荎 酚, 再与苯乙烯发生氧化/加成去芳香化反应. 同时, 该

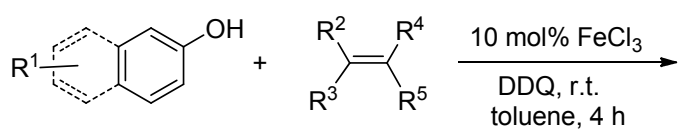

$$
\begin{aligned}
& \overbrace{R^{3} R^{2}}^{R^{2}}
\end{aligned}
$$

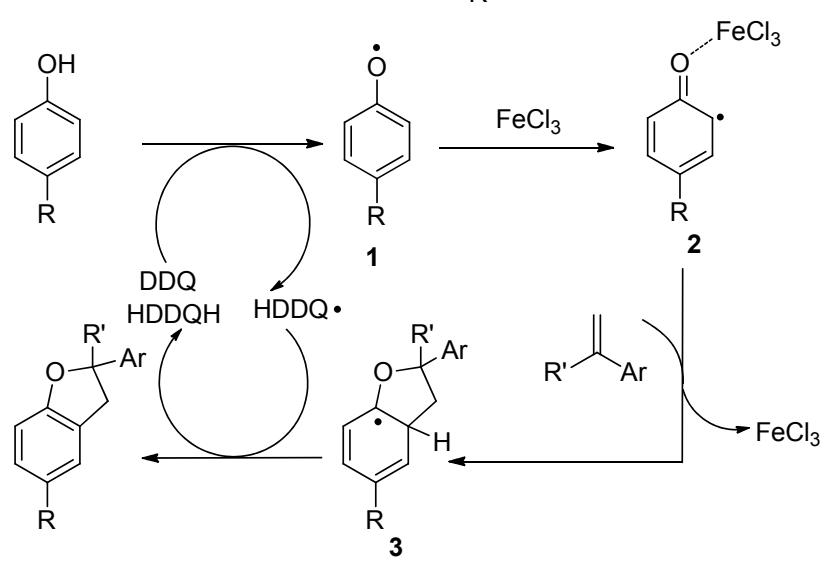

图式 $1 \mathrm{FeCl}_{3}$ 催化苯酚与烯烃的氧化交叉偶联/环化反应

Scheme $1 \quad \mathrm{FeCl}_{3}$-catalyzed oxidative cross-coupling/cyclization reaction of phenols and olefins

课题组比较了无水 $\mathrm{FeCl}_{3}$ 和 $\mathrm{FeCl}_{3} \cdot\left(\mathrm{H}_{2} \mathrm{O}\right)_{6}$ 的催化反应, 发现 $\mathrm{FeCl}_{3} \cdot\left(\mathrm{H}_{2} \mathrm{O}\right)_{6}$ 的催化效果较好, 从而推测出水在质 子传输过程中起着重要作用. Pappo 课题组 ${ }^{[14]}$ 后续的研 究工作表明, 氟醇类溶剂可以提高铁催化的苯酚交叉偶 联反应的效率和选择性. 


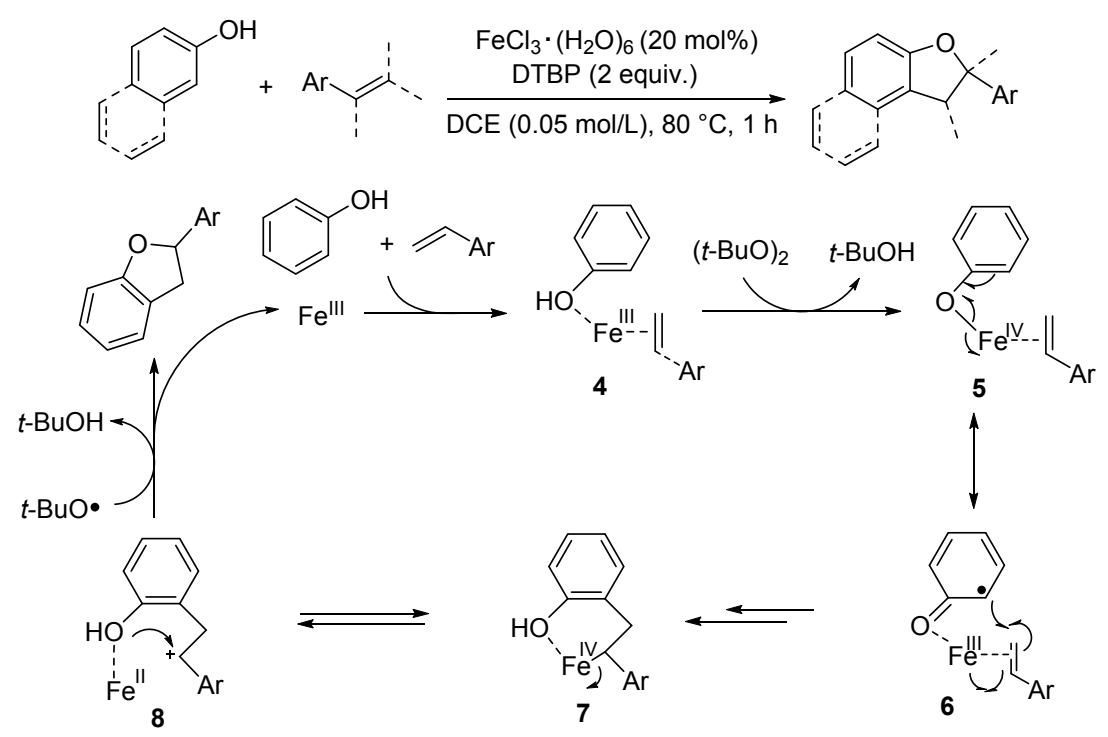

图式 $2 \mathrm{FeCl}_{3} \cdot\left(\mathrm{H}_{2} \mathrm{O}\right)_{6}$ 催化苯酚与烯烃的氧化交叉偶联反应

Scheme $2 \mathrm{FeCl}_{3} \cdot\left(\mathrm{H}_{2} \mathrm{O}\right)_{6}$-catalyzed oxidative cross-coupling reaction of phenols and olefins

Pappo 课题组在实验研究基础上推测该反应是以铁 螯合的自由基偶联机理进行的. 首先, $\mathrm{FeCl}_{3} \cdot\left(\mathrm{H}_{2} \mathrm{O}\right)_{6}$ 与酚 和烯烃形成的螯合物 4, 被二叔丁基过氧化物(DTBP)氧 化经中间体 5 形成亲电的自由基中间体 $\mathbf{6}$, 接着 $\mathbf{6}$ 与烯 烃发生自由基加成反应并经酮式互变异构成烯醇式生 成中间体 7, 随后 7 发生还原消除反应经由茮基阳离子 中间体 8, 最终生成目标化合物二氢苯并呋喃类化合物.

\section{2 三氟甲磺酸催化}

2013 年 Lei 课题组 ${ }^{[15]}$ 也报道了三氟甲磺酸(HOTf) 催化苯醌与烯烃的协同氧化/[3+2]环化反应(Scheme 3). 在 HOTf 作用下, 苯醌首先与一分子的烯烃发生 [3+2] 环化反应, 形成 2,3-二氢苯并呋喃-5-醇中间体, 接着该 中间体在 HOTf 为催化剂, 苯醌为氧化剂条件下与另外 一分子烯烃发生氧化环化反应, 形成最终的四氢苯并二

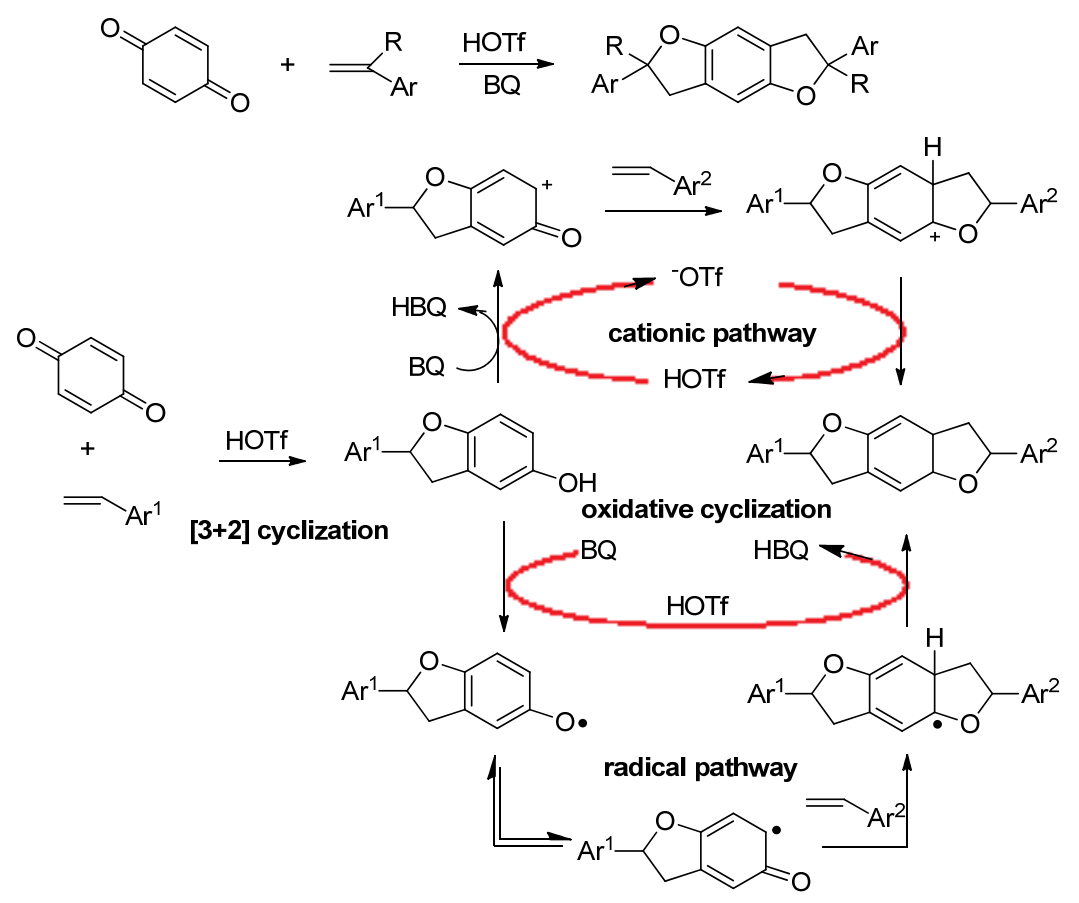

$\mathrm{BQ}$ : benzoquinone; $\mathrm{HBQ}$ : hydroquinone

图式 3 三氟甲磺酸催化苯醌与烯烃的氧化/[3+2]环化反应

Scheme 3 HOTf-catalyzed oxidative/[3+2] cyclization of quinones and olefins 
呋喃. 该反应底物适用范围较广, 一锅条件下制备的四 氢苯并二呋喃可以是对称的, 也可以是不对称的. 如 Scheme 3 所示, 2,3-二氢苯并呋喃-5-醇中间体与烯烃的 氧化环化反应可通过阳离子或自由基途径形成最终产 物四氢苯并二呋喃类化合物.

\section{3 光催化}

2014 年, Yoon 等 ${ }^{[16]}$ 报道了可见光引发的过渡金属 配合物 $\mathrm{Ru}(\mathrm{bpz})_{3}\left(\mathrm{PF}_{6}\right)_{2}$ 催化 $\left(\mathrm{NH}_{4}\right)_{2} \mathrm{~S}_{2} \mathrm{O}_{8}$ 参与的苯酚与烯 烃的氧化 $[3+2]$ 环加成反应(Scheme 4). 该反应适用于 多种富电子的苯酚、萗酚和苯乙烯类化合物. 研究推测 该反应可能机理如下: 以苯酚 9 和烯烃 12 为例, 钉配合 物 $\mathrm{Ru}(\mathrm{bpz})_{3}\left(\mathrm{PF}_{6}\right)_{2}$ 首先和 $\left(\mathrm{NH}_{4}\right)_{2} \mathrm{~S}_{2} \mathrm{O}_{8}$ 发生复分解反应产 生沉淀 $\mathrm{Ru}(\mathrm{bpz})_{3}\left(\mathrm{~S}_{2} \mathrm{O}_{8}\right)$, 可见光条件下, 受激发的 $\mathrm{Ru}(\mathrm{bpz})_{3}\left(\mathrm{~S}_{2} \mathrm{O}_{8}\right)$ 发生氧化猝灭形成活性氧化剂 $\mathrm{Ru}(\mathrm{bpz})_{3}\left(\mathrm{SO}_{4}\right)^{+}$, 接着 $\mathrm{Ru}(\mathrm{bpz})_{3}\left(\mathrm{SO}_{4}\right)^{+}$将苯酚 9 氧化成自 由基阳离子 10 , 再进一步被氧化并失去一个质子形成 共振稳定的苯氧正离子 11, 11 再与烯烃 12 发生 [3+2] 环加成反应得到目标产物 13 . 同时, 活性氧化剂 $\mathrm{Ru}(\mathrm{bpz})_{3}\left(\mathrm{SO}_{4}\right)^{+}$被还原形成 $\mathrm{Ru}(\mathrm{bpz})_{3}\left(\mathrm{SO}_{4}\right)$, 接着再与 $\left(\mathrm{NH}_{4}\right)_{2} \mathrm{~S}_{2} \mathrm{O}_{8}$ 发生复分解反应并循环催化该氧化环加成反 应. 底物研究发现, 该反应需要富电子的 2-或 4-烷氧基 苯酚, 因为该类苯酚氧化生成的苯氧正离子 11 较为稳 定，这也证明了反应中间体 11 的存在.

Liu 和 Wang 等 ${ }^{[17]}$ 于 2013 年首次报道在可见光条件 下, 介孔石墨型氮化碳 $\left(\mathrm{mpg}-\mathrm{C}_{3} \mathrm{~N}_{4}\right)$ 催化, 空气氧化室温 条件下实现了白荺芦醇及其类似物的氧化偶联反应
(Scheme 5), 为 $\delta$-葡萄素(16)及其类似物提供了一种简 洁、高效、绿色的合成方法，也是非均相光催化首次用 于该类氧化偶联反应. 该反应机理如 Scheme 5 所示: 在 可见光照射条件下, mpg- $\mathrm{C}_{3} \mathrm{~N}_{4}$ 上的电子受激发后从价带 跃迁到导带上，从而使得导带上具有电子，价带上产生 了电子空穴. 空气中的氧气在导带上得到电子形成 $\mathrm{O}_{2}{ }^{-}$, $\mathrm{O}_{2}{ }^{-}$与白僽芦醇 14 反应形成 14 、或者 14 与碱作用产生 $14^{-}, 14^{-}$再将电子转移给价键上的电子空穴形成 $14^{\circ}, 14^{\circ}$ 离域形成的醌类自由基 $M_{5}$ 和苠基自由基 $M_{10}$ 发生偶联 并互变异构得到中间体 $\mathbf{1 5}$, 接着 15 发生分子内的共轭 加成并失去一个质子得到 $\delta$-葡萄素 $\mathbf{1 6}$.

\section{2 直接氧化环化反应}

\section{1 过硫酸钠氧化}

2015 年, $\mathrm{Xia}$ 等 ${ }^{[18]}$ 报道了通过 $\mathrm{Na}_{2} \mathrm{~S}_{2} \mathrm{O}_{8}$ 参与的三甲 基硅(TMS)保护的苯酚与烯烃的氧化偶联反应来制备二 氢苯并呋喃类化合物，并用该方法以 $21 \%$ 的产率一步制 备了天然产物 corsifuran A (Scheme 6). 该方法主要适用 于 TMS 保护的对甲氧基苯酚以及苯乙烯的衍生物, 避 免了使用金属催化剂, 而是通过 $\mathrm{Na}_{2} \mathrm{~S}_{2} \mathrm{O}_{8}$ 直接氧化简单 高效地实现了苯酚和烯烃的氧化环加成反应.

反应可能的机理如 Scheme 6 所示: 过硫酸根在加 热条件下将 TMS 保护的对甲氧基苯酚 17 氧化成自由基 阳离子 18, 同时过二硫酸根被还原成 $\mathrm{SO}_{4}{ }^{--}, \mathbf{1 8}$ 消除 $\mathrm{TMS}^{+}$后得到的酚氧自由基 19 离域形成碳自由基 $\mathbf{2 0}$, 这 时有两种可能的反应途径: 一是碳自由基 20 与苯乙烯

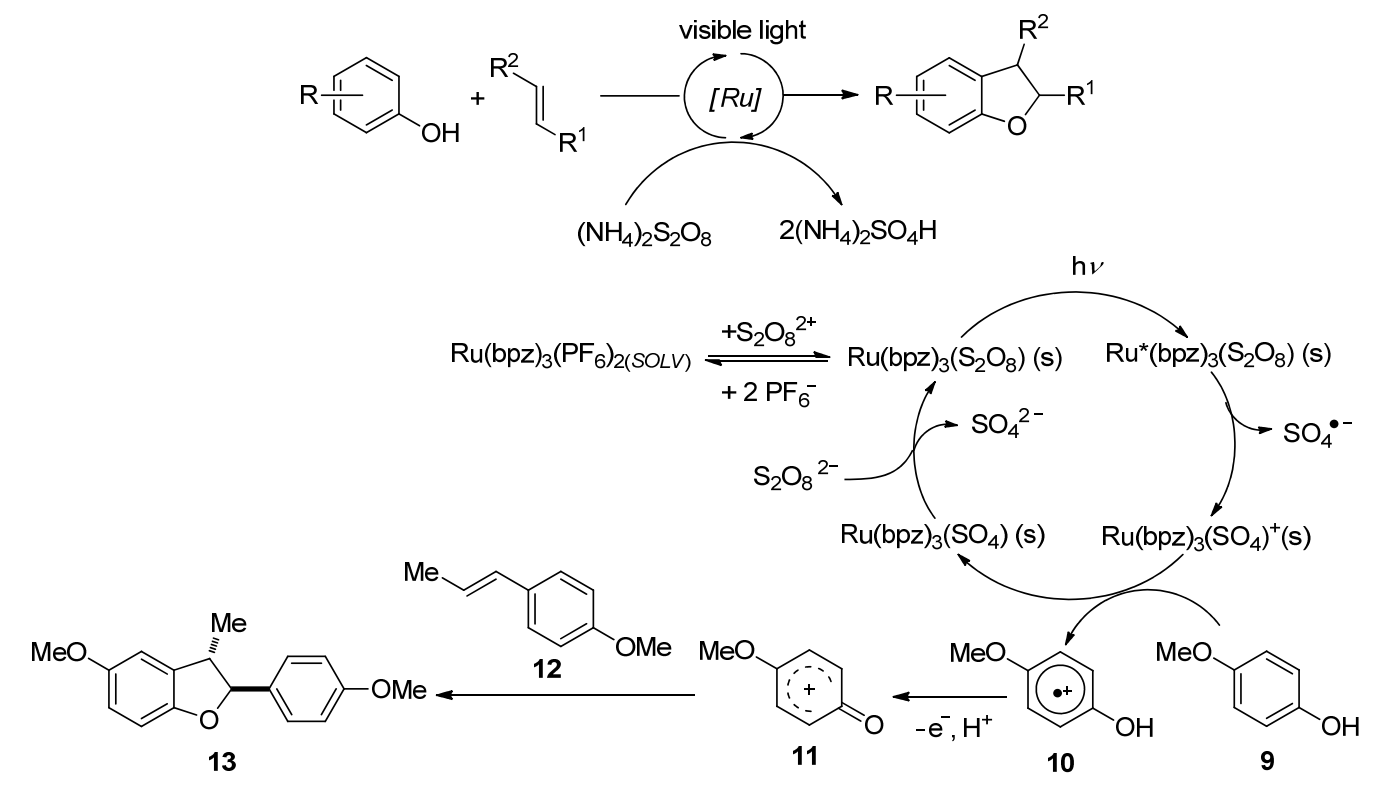

图式 $4 \mathrm{Ru}(\mathrm{bpz})_{3}\left(\mathrm{PF}_{6}\right)_{2}$ 光催化苯酚与烯烃的氧化 $[3+2]$ 环加成反应

Scheme 4 Oxidative $[3+2]$ cycloaddition reaction of phenols and olefins using $\mathrm{Ru}(\mathrm{bpz})_{3}\left(\mathrm{PF}_{6}\right)_{2}$ as photocatalyst 


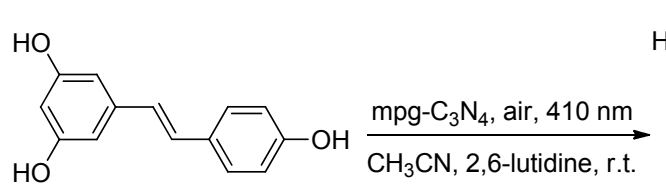

14<smiles>Oc1ccc(C2Oc3ccc(/C=C/c4cc(O)cc(O)c4)cc3C(c3cc(O)cc(O)c3)O2)cc1</smiles>

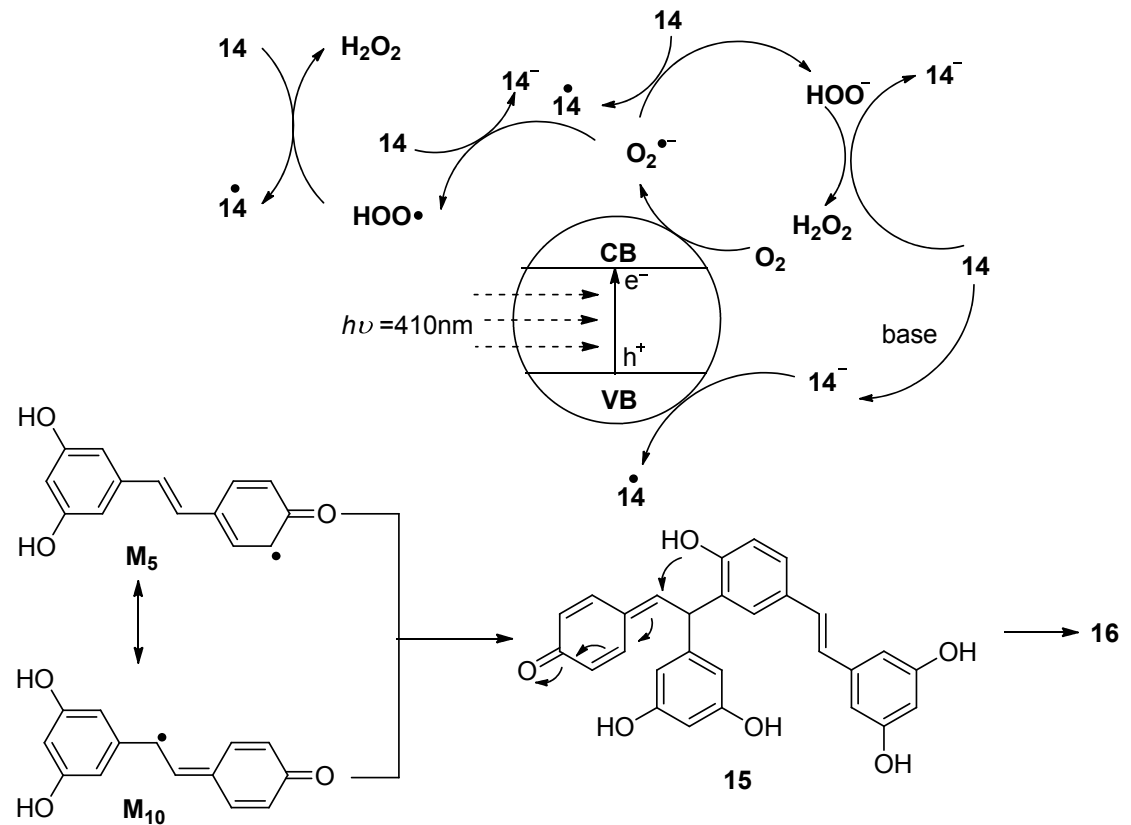

图式 $5 \mathrm{mpg}-\mathrm{C}_{3} \mathrm{~N}_{4}$ 光催化白藜芦醇的氧化偶联反应

Scheme 5 Oxidative coupling reaction of resveratrol using mpg- $\mathrm{C}_{3} \mathrm{~N}_{4}$ as photocatalyst<smiles>[R1]Oc1ccc(OC)cc1</smiles><smiles>[R]C([R])=C1C=CC=[Y]1[H]</smiles>

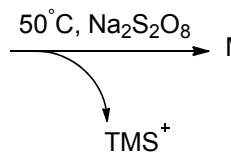<smiles>[R]c1cc2c(cc1OC)C([R])(c1ccc[Y]1[H])C2[Y]</smiles><smiles>COc1ccc(C2Cc3cc(OC)ccc3O2)cc1</smiles>

corsifuran A

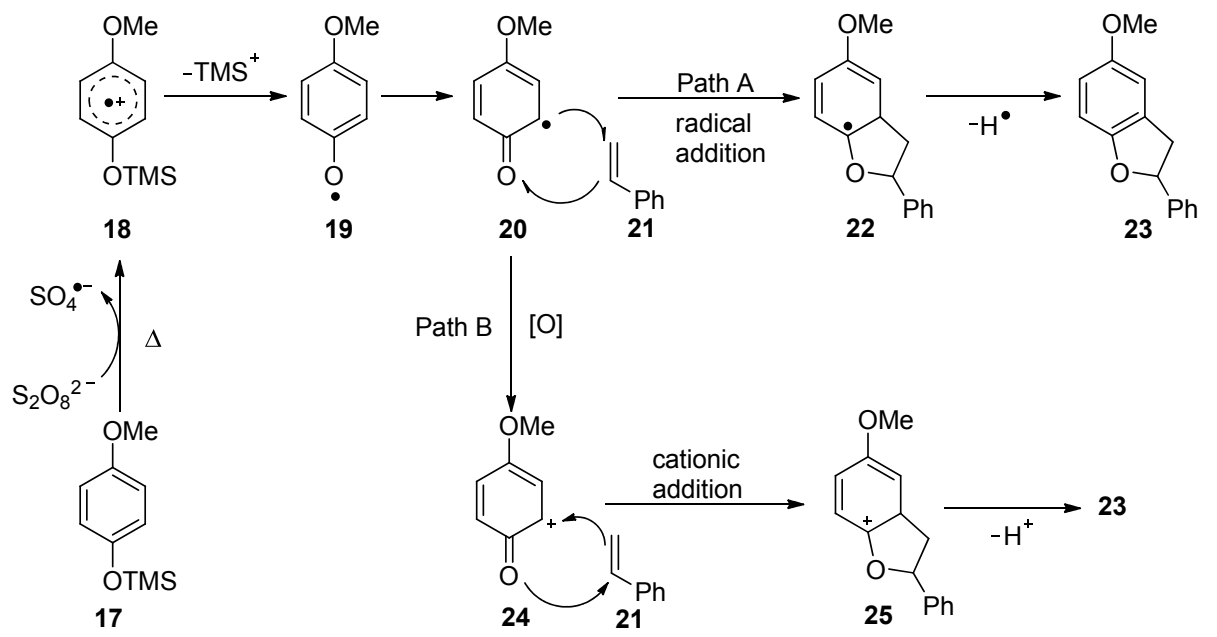

图式 $6 \mathrm{Na}_{2} \mathrm{~S}_{2} \mathrm{O}_{8}$ 促进的苯酚与烯烃的 $[3+2]$ 氧化偶联反应

Scheme $6[3+2]$ oxidative coupling reaction of phenols and olefins promoted by $\mathrm{Na}_{2} \mathrm{~S}_{2} \mathrm{O}_{8}$ 
21 发生[3+2]自由基加成反应得到环状的自由基中间 体 22, 接着再失去一个氢自由基得到目标产物 23 (Path A). 另一种可能是中间体 $\mathbf{2 0}$ 继续被氧化形成阳离子 $\mathbf{2 4}$, 24 再与烯烃 21 发生[3+2]环加成反应得到阳离子中间 体 25, 25 失去一个质子便得到了相应的目标产物 23 (Path B).

\section{2 高价磑(III)氧化}

1991 年 Swenton 等 ${ }^{[19]}$ 报道了用乙腈作溶剂, $\mathrm{PhI}(\mathrm{OAc})_{2}$ 或 $\mathrm{PhI}\left(\mathrm{OOCCF}_{3}\right)_{2}$ 参与的对甲氧基苯酚类化合 物与富电子苯乙烯衍生物的氧化环加成反应(Scheme 7). 研究发现, $\mathrm{PhI}\left(\mathrm{OOCCF}_{3}\right)_{2}$ 比 $\mathrm{PhI}(\mathrm{OAc})_{2}$ 作氧化剂时, 反应效果较好, 间甲氧基苯酚与富电子苯乙烯不能发生 该反应，同时 $E$ 式或 $Z$ 式的苯乙烯衍生物都得到反式的 二氢苯并呋喃衍生物. 因此作者推测该反应经过中间体 27 , 双键立体化学消失, 因此只得到了反式的二氢呋喃 类化合物 26.

1992 年 Swenton 课题组 ${ }^{[20]}$ 又用电化学阳极氧化方 法研究了对甲氧基苯酚与富电子苯乙烯和丙烯基苯衍 生物的氧化环加成反应. 实验结果表明, 该反应以较高 产率得到反式二氢苯并呋喃类化合物; 4-甲氧基萗酚的 反应产率也较高, 但 1-菜酚和 2-菜酚的反应产率很低; $E$ 式或 $Z$ 式的 1,2-二甲氧基-4-丙烯基苯在该反应中都以类 似产率得到相应的反式二氢苯并呋喃类化合物; 将电化 学阳极氧化与 $\mathrm{PhI}\left(\mathrm{OOCCF}_{3}\right)_{2}$ 参与的该类反应相比较, $\mathrm{PhI}\left(\mathrm{OOCCF}_{3}\right)_{2}$ 的整体反应产率较高, 底物适用范围也 较广泛. 电化学阳极氧化反应可能的机理与 Scheme 4 类似, 反应当中苯酚先被氧化形成的相应苯氧正离子 11, 接着再与苯乙烯发生环加成反应, 形成了相应的二 氢苯并呋喃类化合物.

2008 年 Canesi 等 ${ }^{[21]}$ 报道了以 $\mathrm{PhI}(\mathrm{OAc})_{2}$ 为氧化剂, 氟代醇为溶剂条件下苯酚衍生物与富电子的烯烃, 烯丙 基硅烷和呋喃的 $[3+2]$ 环加成反应(Scheme 8). 其中, 取 代的苯酚、 $\beta$-荎酚都可以与富电子的苯乙烯类化合物,
二氢呋喃或二氢吡喃, 烯丙基硅烷和呋喃发生氧化环加 成反应, 生成相应的二氢苯并呋喃、四氢呋喃苯并呋喃、 四氢吡喃苯并呋喃、二氢呋喃苯并呋喃以及相关的活性 天然产物等. 和 Swenton 课题组的工作相比，该反应底 物适用范围较广，作者推测可能的原因是氟代醇这类质 子性溶剂，使得反应中间体 28 比较稳定而引起. 其中, 苯酚与环状烯醇醚反应时，溶剂选用六氟异丙醇(HFIP) 比三氟乙醇(TFE)效果好; 与呋喃反应时, TFE 或呋喃作 溶剂反应效果较好. 环状烯醇醚类化合物与呋喃相比 较, 呋喃与苯酚衍生物反应效果较好。除了二氢苯并呋 喃结构外，该研究工作一步构建的二氢呋喃苯并呋喃和 四氢呋喃苯并呋喃等结构, 是许多活性天然产物的核心 骨架 ${ }^{[22]}$. 例如拒食剂 panacene 和具有抗癌活性的 psorofebrin 中就含有的二氢呋喃苯并呋喃骨架; Aspergillus flavus(黄曲霉)的食源性致突变代谢物 aflatoxin $\mathrm{B}_{2}$ 和从 Aspergillus parasiticus 中提取出来的 versicolorin $\mathrm{B}_{2}$ 中含有的四氢呋喃苯并呋喃核心骨架(图 2).

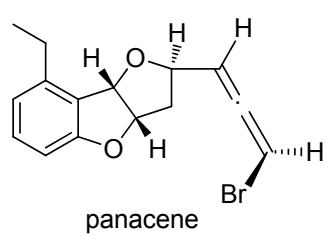<smiles>COc1cc2c(c3oc4c(O)cccc4c(=O)c13)[C@@H]1OC[C@](C)(O)[C@H]1O2</smiles><smiles>COc1cc2c(c3oc(=O)c4c(c13)CCC4=O)[C@@H]1CCO[C@H]1O2</smiles><smiles>O=C1c2cc(O)cc(O)c2C(=O)c2c1cc1c(c2O)[C@@H]2CCO[C@H]2O1</smiles>

图 2 Panacene, psorofebrin, aflatoxin $B_{2}$ 和 versicolorin $B_{2}$ 的 结构

Figure 2 Structures of panacene, psorofebrin, aflatoxin $\mathrm{B}_{2}$ and versicolorin $\mathrm{B}_{2}$

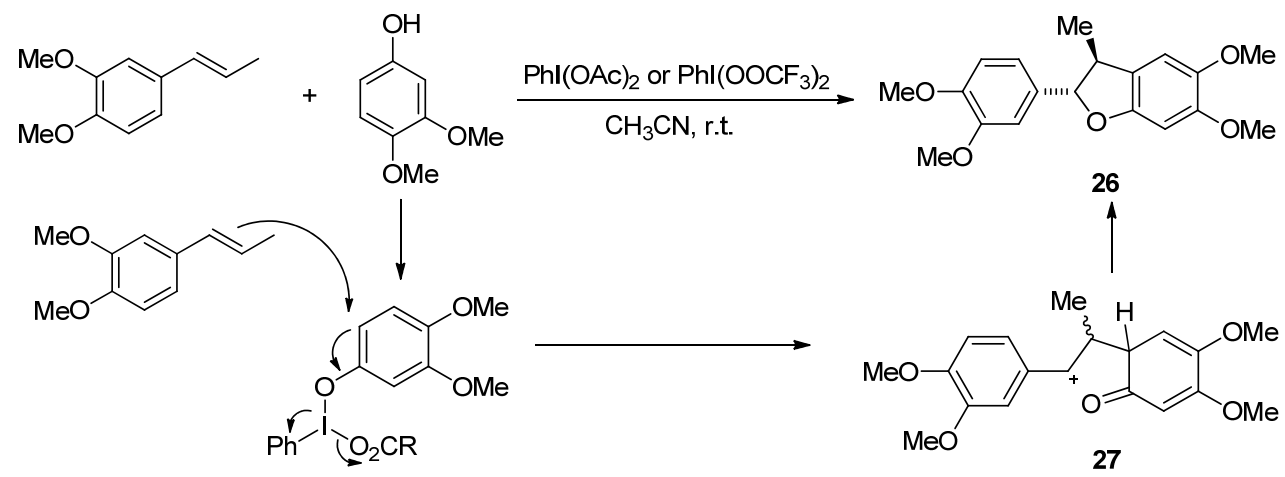

图式 $7 \mathrm{PhI}(\mathrm{OAc})_{2}$ 和 $\mathrm{PhI}\left(\mathrm{OOCCF}_{3}\right)_{2}$ 促进苯酚与烯烃的氧化环加成反应

Scheme 7 Oxidative cycloaddition reaction of phenols and olefins promoted by $\mathrm{PhI}(\mathrm{OAc})_{2}$ and $\mathrm{PhI}\left(\mathrm{OOCCF}_{3}\right)_{2}$ 
<smiles>C=CC1=CC(=O)C([C@H](C(=O)OC)c2ccc(OC)cc2)C=C1C(=O)C=Cc1ccc(O)cc1</smiles>

28<smiles>COc1ccc([C]c2cc(OC)ccc2O)cc1</smiles><smiles>[R]c1ccc(O)cc1</smiles><smiles>[R]c1ccc(O)cc1</smiles><smiles>[R]c1ccc(O)cc1</smiles>

图式 $8 \mathrm{PhI}(\mathrm{OAc})_{2}$ 促进苯酚与富电子烯烃、烯丙基硅烷和呋 喃的 $[3+2]$ 环加成反应

Scheme 8 [3+2] cycloaddition reaction of phenols with electron-rich olefins, allylsilanes and furan promoted by $\mathrm{PhI}(\mathrm{OAc})_{2}$

此外, $\mathrm{PhI}(\mathrm{OAc})_{2}$ 参与的异丁子香酚的氧化偶联反 应可以合成天然产物 dehydrodiisoeugenol, 并可以进一 步用于 salvinal 和 fragnasols A, B, C 等天然产物的合 成 ${ }^{[23]}(\mathrm{Eq} .1)$.<smiles>C/C=C/c1cc(OC)c2c(c1)C(C)[C@@H](c1ccc(O)c(OC)c1)O2</smiles><smiles>[R2]c1cc(OC)c2c(c1)C(C)[C@H](c1ccc(OC)c(OC)c1)O2</smiles>

fragnasols $A: \mathrm{R}^{1}=$ erythro- $\mathrm{CH}(\mathrm{OMe}) \mathrm{CH}(\mathrm{OH}) \mathrm{Me} ; \mathrm{R}^{2}=\mathrm{H}$

fragnasols $\mathrm{B}: \mathrm{R}^{1}=\mathrm{CH}_{2} \mathrm{CH}_{2} \mathrm{OH} ; \mathrm{R}^{2}=\mathrm{H}$

fragnasols $\mathrm{C}: \mathrm{R}^{1}=(E)-\mathrm{CH}=\mathrm{CHCH}_{2} \mathrm{OH} ; \mathrm{R}^{2}=\mathrm{Me}$
2008 年 Morrow 等 ${ }^{[24]}$ 报道了 4-烷氧基苯酚或 4-甲氧 基萘酚与 7-甲氧基-1,2-二氢萘或 7-甲氧基- $2 H$-苯并吡喃 在 $\mathrm{PhI}\left(\mathrm{OOCCF}_{3}\right)_{2}$ 作用的氧化环加成反应, 得到 5-碳紫 檀素或紫檀素类化合物(Scheme 9). 机理研究表明，该 反应也通过酚氧正离子的环加成反应进行的.

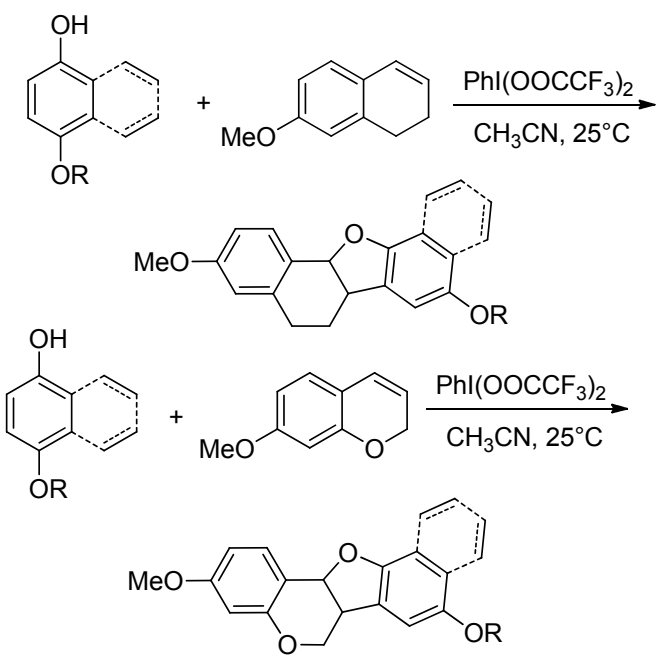

图式9 $\mathrm{PhI}\left(\mathrm{OOCCF}_{3}\right)_{2}$ 促进酚类化合物与二氢萘或 $2 H$-苯并吡 喃的氧化环加成反应

Scheme 9 Oxidaive cycloaddition reaction of phenols and dihydronaphthalene or $2 \mathrm{H}$-chromene promoted by $\mathrm{PhI}\left(\mathrm{OOCCF}_{3}\right)_{2}$

2015 年, Kita 等 ${ }^{[25]}$ 用一种新的高价碘试剂 $\left[\mathrm{Ph}\left(\mathrm{CF}_{3} \mathrm{COO}\right) \mathrm{I}\right]-\mathrm{O}-\left[\mathrm{I}\left(\mathrm{OOCCF}_{3}\right) \mathrm{Ph}\right](\mathrm{PIFA}$ dimer)研究了苯 酚和苯胺与烯烃的氧化环加成反应(Eq. 2). 研究发现, 以乙腈为溶剂, 对甲氧基苯酚和对甲氧基苯乙烯反应, 用 PIFA dimer 作氧化剂所得产物产率比 $\mathrm{PhI}\left(\mathrm{OOCCF}_{3}\right)_{2}$ 作氧化剂高出 $20 \%$ 左右. 随后研究表明, 该反应适用于 多取代的对甲氧基苯酚、4-甲氧基䒺酚和多取代的苯乙 烯衍生物, 其中酚羟基邻位取代基的位阻效应和电子效 应对反应产率的影响比较大, 而且三氟乙醇比乙腈作溶 剂时反应产率有所提高. PIFA dimer 比 $\mathrm{PhI}\left(\mathrm{OOCCF}_{3}\right)_{2}$ 反 应活性高，作者推测可能的原因是 PIFA dimer 中 $\mathrm{I}^{-} \mathrm{OCOCF}_{3}$ 键极性强于 $\mathrm{PhI}\left(\mathrm{OOCCF}_{3}\right)_{2}$ 中的, 从而使其 中碘原子的正电性更强，更容易与苯酚中的氧原子结合 形成过渡中间体. 同时, 作者将该 PIFA dimer 的氧化体

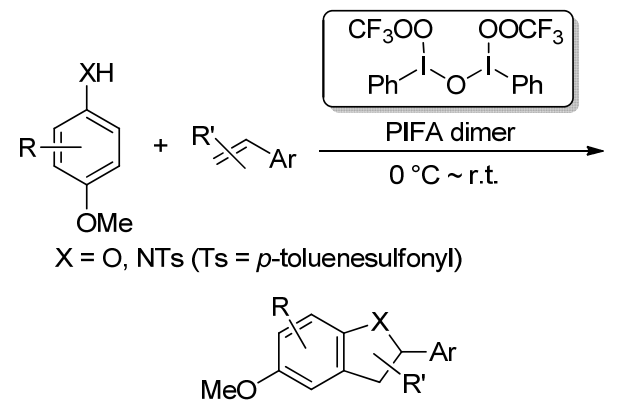


系拓展到对甲苯磺酰基保护的对甲氧基苯胺和五元环 状烯胺与对甲氧基苯乙烯的反应, 成功地一步构建了二 氢吲哚骨架和吲哚并吡咯骨架, 为含有相关骨架的生物 活性药物或天然产物的合成提供了新方法.

\section{3 硝酸铈铵氧化}

2013 年, Wang 等 ${ }^{[26]}$ 报道了硝酸铈铵 $(\mathrm{CAN})$ 参与的 对乙烯基苯酚类化合物的氧化二聚反应, 制备了一系列 反式二氢苯并呋喃类化合物, 其中包括 conocarpan, licarin A 和 acuminatin 这三个天然产物(Scheme 10). 这 类反应中硝酸铈铵为 1.5 equiv. 且逐渐加入, 反应时间为 $0.5 \mathrm{~h}$ 时反应效果最好, 其中硝酸铈铵量增大或者反应 时间延长都会影响该二聚反应. 反应可能的机理如 Scheme 10 所示: 苯酚 29 被硝酸铈铵氧化形成自由基阳 离子 30, 接着 30 的共振式 31 与 29 发生自由基偶联反 应得到 32, 32 失去氢自由基得到 33 , 最后 33 经过分子 内的共轭加成反应并失去质子得到反式的二氢苯并呋 喃类化合物 35 .

\section{$2.4 \mathrm{DDQ}$ 及其类似物氧化}

2008 年, Janin 课题组 ${ }^{[27]}$ 在研究 furo[3,2-f]chrome 类
似物的合成和抗菌活性研究中, 用 DDQ 氧化 2,5-二羟 基苯甲醛得到 2-甲酰基苯醌，接着向反应体系中加入不 同的烯醇醚衍生物，从而通过 2-甲酰基苯醌和烯醇醚的 $[3+2]$ 环加成反应得到相应的二氢苯并呋喃类化合物 (Scheme 11). 该反应要求烯醇醚过量, 反应产率整体较 低，适用的烯醇醚种类较少，当用 1,1-二乙氧基乙烯和 三甲基硅基烯醇醚时，直接生成相应的苯并呋喃类化合 物. 2009 年, Zhou 和 Fang 课题组 ${ }^{[28]}$ 在研究白藜芦醇及其 类似物的自由基捕捉活性和机理研究中, 发现和 DDQ 结构类似的加尔万氧自由基也能够将白藜芦醇及其类 似物氧化二聚形成相应的 $\delta$-葡萄素 16 及其类似物.

\section{5 醋酸银, 氧化银和氯化铁等金属盐或金属氧化物} 氧化

白藜芦醇及其类似物的氧化二聚反应中常用醋酸 银、氧化银和氯化铁等金属盐或金属氧化物等作氧化 剂 $^{[29]}$. 2004 年 Sako 等 ${ }^{[29 a]}$ 报道了 AgOAc 参与的白䓠芦 醇的自身氧化偶联反应，以 $97 \%$ 的产率得到 $\delta$-葡萄素 $\mathbf{1 6}$ (Scheme 12). 由于 AgOAc 在大部分有机溶剂中的溶解 性很小, 因此该反应的有效性主要取决于溶剂, 实验发<smiles>[R1]C=Cc1ccc(O)c([R])c1</smiles>

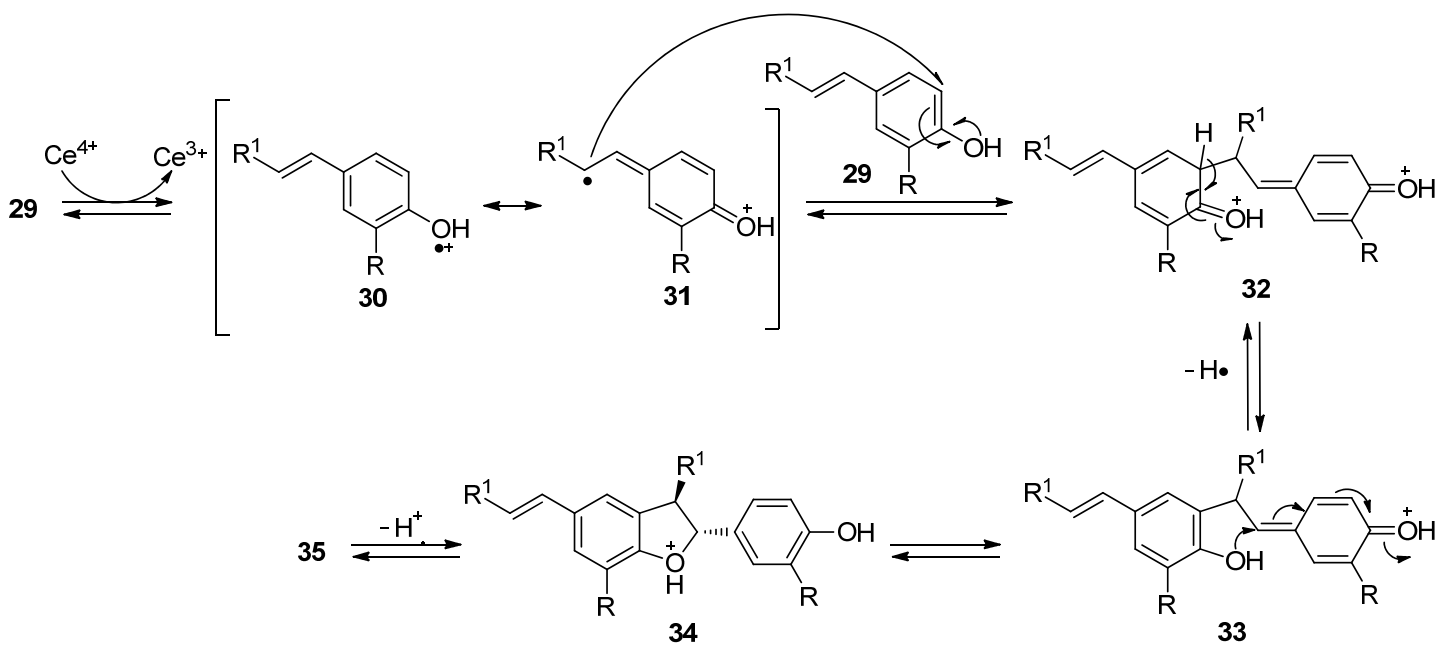

图式 10 硝酸铈铵促进对乙烯基苯酚的氧化二聚反应

Scheme 10 Oxidative dimerization of $p$-alkenylphenols promoted by cerium ammonium nitrate<smiles>[R]C=C([R])CC</smiles>

图式 11 DDQ 促进 2,5-二羟基苯甲醛与烯醇醚的的氧化环加成反应

Scheme 11 Oxidative cycloaddition reaction of 2,5-dihydrobenzaldehyde and enol ethers promoted by DDQ 
现甲醇是最佳溶剂. 在该研究工作中, 作者把 $\mathrm{AgOAc}$ 与其它的氧化剂, 例如 $\mathrm{Ag}_{2} \mathrm{O}, \mathrm{Ag}_{2} \mathrm{CO}_{3}, \mathrm{AgNO}_{3}$, $\mathrm{Mn}(\mathrm{OAc})_{3}, \mathrm{CuOAc}, \mathrm{K}_{3} \mathrm{Fe}(\mathrm{CN})_{6}, \mathrm{DDQ}$ 和 $\mathrm{PhI}(\mathrm{OAc})_{2}$ 做了 比较, 结果发现 $\mathrm{AgOAc}$ 的氧化偶联效果最好. 该反应 可能的机理如 Scheme 12 所示: 首先 $\mathrm{AgOAc}$ 氧化白藜芦 醇并脱去质子形成酚氧自由基，接着该自由基共振并区 域选择性地发生偶联, 然后经分子内环化最终得到 $\delta$-葡 萄素 $\mathbf{1 6 .}$

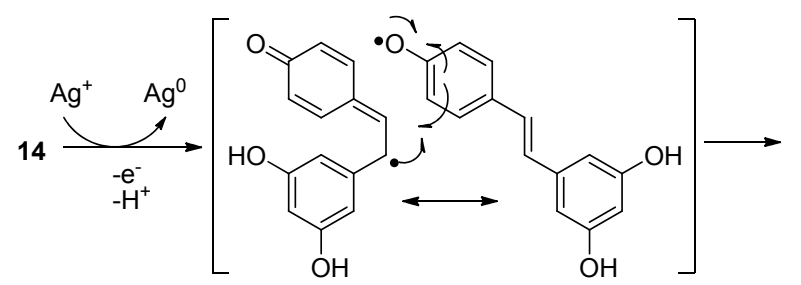<smiles>O=C1C=CC(=O)C(C(c2cc(O)cc(O)c2)C2CCCCC2)C1</smiles>

图式 $12 \mathrm{AgOAc}$ 促进白藜芦醇的二聚反应

Scheme 12 Oxidative dimerization of resveratrol promoted by $\mathrm{AgOAc}$
2005 年 Niwa 等 ${ }^{[29 b]}$ 也报道了白藜芦醇的仿生转化. 使用几种无机氧化剂和过氧化物酶研究发现, 白藜芦醇 在 $\mathrm{Tl}\left(\mathrm{NO}_{3}\right)_{3} / \mathrm{CH}_{3} \mathrm{OH}$ 体系中以 $68 \%$ 产率得到 $\varepsilon$-葡萄素 $\mathbf{3 6}$, 在 $\mathrm{FeCl}_{3}$ /丙酮和 $\mathrm{MnO}_{2} / \mathrm{CH}_{2} \mathrm{Cl}_{2}$ 体系中, 得到反式的 $\delta$-葡 萄素(16); 在过氧化物酶体系中主要得到得到 $\delta$-葡萄素 16 和 pallidol 37 的混合物(图 3).

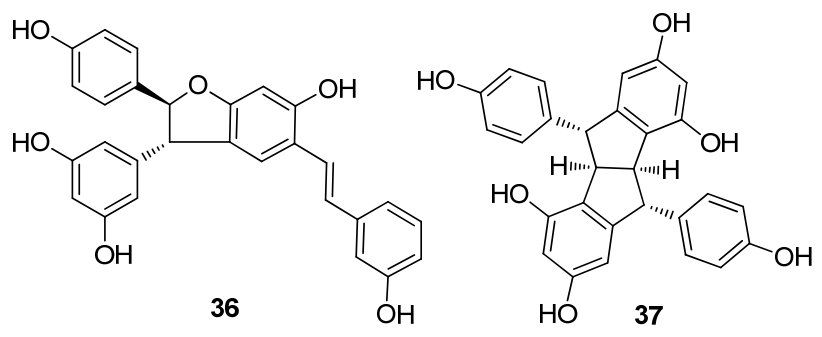

图 $3 \varepsilon$-葡萄素 $\mathbf{3 6}$ 和 pallidol $\mathbf{3 7}$ 的结构

Figure 3 Structures of $\varepsilon$-viniferin 36 and pallidol 37

2006 年, Rindone 等 ${ }^{[29 c]}$ 报道了酚类化合物在 Evans 2-噁唑烷酮手性辅基作用下的不对称氧化偶联反应 (Scheme 13). 作者首先将阿魏酸 38 和手性 2-噁唑烷酮 39a 39d 反应得到手性化合物 40a 40d, 接着 40a 40d 在 $\mathrm{HRP} / \mathrm{H}_{2} \mathrm{O}_{2}$ 或者 $\mathrm{Ag}_{2} \mathrm{O}$ 作用下发生双分子自由基偶 联反应得到一对非对映异构体 41a 41d 和 42a 42d,
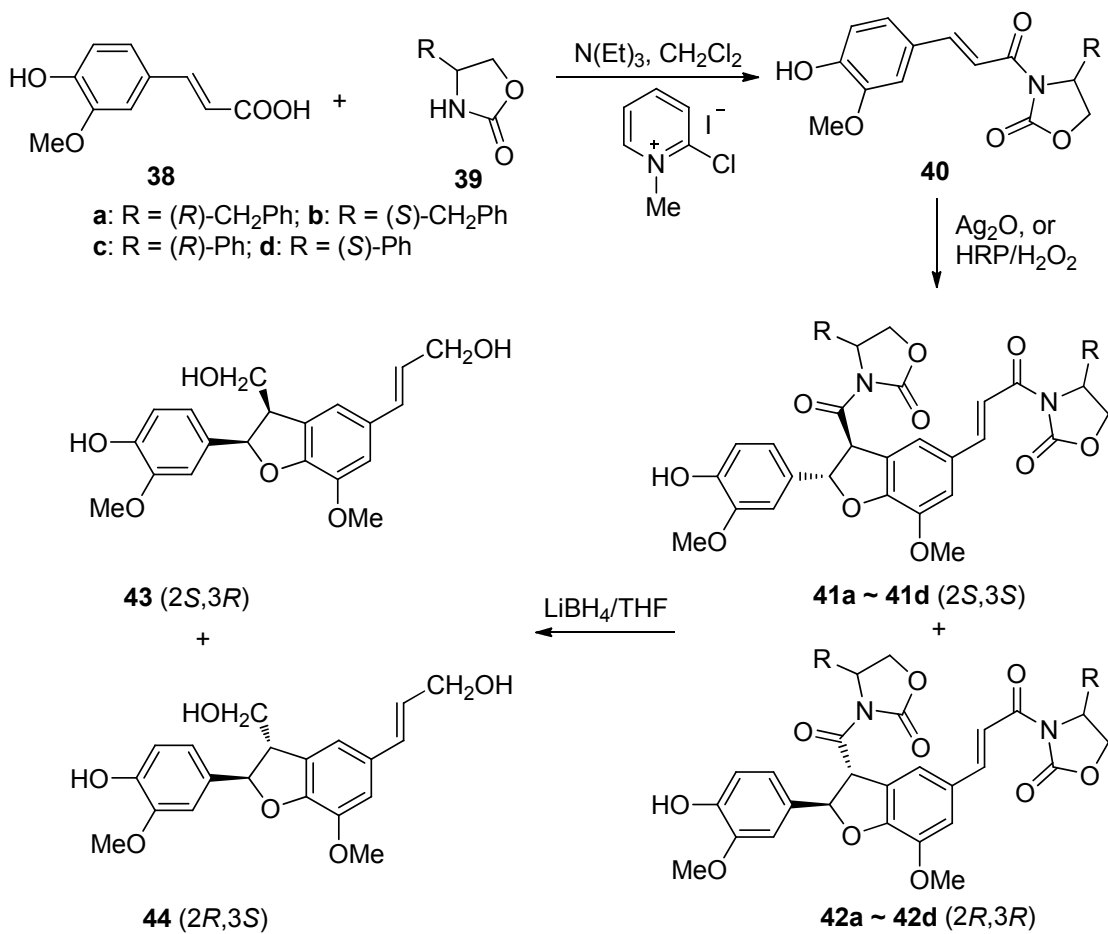<smiles>[R]C1COC(=O)N1C(=O)C=Cc1cc(OC)c2c(c1)[C@H](C(=O)N1C(=O)OCC1[R])[C@H](c1ccc(O)c(OC)c1)O2</smiles>
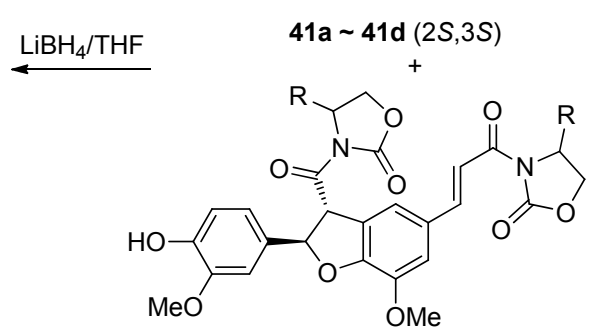

$42 \mathbf{a} \sim 42 \mathrm{~d}(2 R, 3 R)$

图式 15 阿魏酸的立体选择性自由基偶联反应

Scheme 15 Stereoselective radical coupling reaction of ferulic acid 
最后 $\mathrm{LiBH}_{4} / \mathrm{THF}$ 条件下还原脱去手性辅基, 得到含有二 氢苯并呋喃结构的脱氢双松柏醇对映异构体 $\mathbf{4 3}$ 和 $\mathbf{4 4}$, 反应总产率为 $40 \% \sim 50 \%$, 对映异构体过量为 $18 \%$ $62 \%$. 作者推测中间体的稳定差异导致了该对映选择 性. 此外, 2006 年, Youn 等 ${ }^{\left[{ }^{[0]}\right.}$ 报道的 AgOTf 催化苯酚或 芸酚与共轭二烯的反应也可以用来构建二氢苯并呋喃 或二氢苯并吡喃类化合物.

苯酚与烯烃的氧化环加成反应, 除了上述介绍的典 型反应条件, 电化学阳极氧化 ${ }^{[20,31]}$ 、漆酶氧化 ${ }^{[32]}$ 和酶催 化的过氧化物氧化 ${ }^{[29 \mathrm{~d}, 33]}$ 等也可以实现苯酚与烯烃的氧 化环加成反应, 并用于二氢苯并呋喃骨架的构建. 只是 电化学氧化要用专门的电化学装置; 酶催化氧化的实验 条件需要严格控制, 目前也仅用于白藜芦醇及其类似物 的二聚反应, 且反应化学选择性不高. 因此这些方法在 合成上并未得到广泛的应用.

\section{3 结论与展望}

综上所述, 苯酚与烯烃的氧化环加成反应大致可以 分为催化的氧化环加成和直接氧化环加成两类, 相应的 反应机理研究也已取得一定进展, 其中介孔石墨型氮化 碳催化的白著芦醇以及类似物的二聚反应开拓了非均 相催化该类反应的新方法, 但是目前尚未见到非均相催 化苯酚与烯烃环加成反应的系统研究. 考虑到非均相催 化具有催化剂容易分离、可以反复使用等符合绿色化学 和易于工业化应用的优点，因此在现有方法的基础上， 发展一些非均相催化, 廉价氧化剂参与的苯酚与烯烃的 氧化环加成反应, 为二氢苯并呋喃类核心骨架和相关的 天然产物提供绿色，易于工业化的高效合成方法，将是 该类反应发展的一个重要方向.

\section{References}

[1] (a) Fan, R.; Ding, Q.; Ye, Y. Synthesis 2012, 45, 1.

(b) Su, B.; Deng, M.; Wang, Q. Org. Lett. 2013, 15, 1606.

[2] (a) Libman, A.; Shalit, H.; Vainer, Y.; Narute, S.; Kozuch, S.; Pappo, D. J. Am. Chem. Soc. 2015, 137, 11453.

(b) More, N. Y.; Jeganmohan, M. Org. Lett. 2015, 17, 3042.

(c) Matsushita, M.; Kamata, K.; Yamaguchi, K.; Mizuno, N. J. Am. Chem. Soc. 2005, 127, 6632

(d) Morimoto, K.; Sakamoto, K.; Ohnishi, Y.; Miyamoto, T.; Ito, M.; Dohi, T.; Kita, Y. Chem. Eur. J. 2013, 19, 8726.

(e) Elsler, B.; Schollmeyer, D.; Dyballa, K. M.; Franke, R.; Waldvogel, S. R. Angew. Chem., Int. Ed. 2014, 53, 5210.

(f) Lee, Y. E.; Cao, T.; Torruellas, C.; Kozlowski, M. C. J. Am. Chem. Soc. 2014, 136, 6782.

(g) Gaster, E.; Vainer, Y.; Regev, A.; Narute, S.; Sudheendran, K.; Werbeloff, A.; Shalit, H.; Pappo, D. Angew. Chem., Int. Ed. 2015, $54,4198$.

(h) Morimoto, K.; Sakamoto, K.; Ohshika, T.; Dohi, T.; Kita, Y. Angew. Chem., Int. Ed. 2016, 55, 3652.

[3] (a) Seoane, A.; Casanova, N.; Quinones, N.; Mascarenas, J. L.; Gu- lias, M. J. Am. Chem. Soc. 2014, 136, 7607.

(b) Zuo, Z.; Yang, X.; Liu, J.; Nan, J.; Bai, L.; Wang, Y.; Luan, X. J. Org. Chem. 2015, 80, 3349.

[4] (a) Guo, X.; Yu, R.; Li, H.; Li, Z. J. Am. Chem. Soc. 2009, 131, 17387.

(b)Parnes, R.; Kshirsagar, U. A.; Werbeloff, A.; Regev, C.; Pappo, D. Org. Lett. 2012, 14, 3324.

(c)Pappo, D.; Regev, A.; Shalit, H. Synthesis 2015, 47, 1716.

[5] (a) Denizot, N.; Pouilhes, A.; Cucca, M.; Beaud, R.; Guillot, R.; Kouklovsky, C.; Vincent, G. Org. Lett. 2014, 16, 5752.

(b) Tomakinian, T.; Guillot, R.; Kouklovsky, C.; Vincent, G. Angew. Chem., Int. Ed. 2014, 53, 11881 .

(c) Vincent, G.; Beaud, R.; Tomakinian, T.; Denizot, N.; Pouilhès, A.; Kouklovsky, C. Synlett 2014, 26, 432.

[6] Xu, W.; Nachtsheim, B. J. Org. Lett. 2015, 17, 1585.

[7] Lee, H.; Yi, C. S. Eur. J. Org. Chem. 2015, 9, 1899.

[8] (a) Jacquemot, G.; Ménard, M.-A.; L'Homme, C.; Canesi, S. Chem. Sci. 2013, 4, 1287.

(b) Long, R.; Yan, X.; Wu, Z.; Li, Z.; Xiang, H.; Zhou, X. Org. Biomol. Chem. 2015, 13, 3571.

[9] (a) Quideau, S.; Deffieux, D.; Douat-Casassus, C.; Pouységu, L. Angew. Chem., Int. Ed. 2011, 50, 586.

(b) Chong, J.; Poutaraud, A.; Hugueney, P. Plant. Sci. 2009, 177, 143 .

(c) Coy Barrera, E. D.; Cuca, S.; Aacute; rez, L. E. Chem. Pharm. Bull. 2009, 57, 639.

[10] Huang, Z.; Jin, L.; Feng, Y.; Peng, P.; Yi, H.; Lei, A. Angew. Chem., Int. Ed. 2013, 52, 7151.

[11] Tomakinian, T.; Guillot, R.; Kouklovsky, C.; Vincent, G. Angew. Chem., Int. Ed. 2014, 53, 11881.

[12] (a) Liang, K.; Yang, J.; Tong, X.; Shang, W.; Pan, Z.; Xia, C. Org. Lett. 2016, 18, 1474.

(b) Liang, K.; Wu, T.; Xia, C. Org. Biomol. Chem. 2016, 14, 4690.

[13] Kshirsagar, U. A.; Regev, C.; Parnes, R.; Pappo, D. Org. Lett. 2013, 15,3174 .

[14] Gaster, E.; Vainer, Y.; Regev, A.; Narute, S.; Sudheendran, K.; Werbeloff, A.; Shalit, H.; Pappo, D. Angew. Chem., Int. Ed. 2015, $54,4198$.

[15] Meng, L.; Zhang, G.; Liu, C.; Wu, K.; Lei, A. Angew. Chem., Int. Ed. 2013, 52, 10195.

[16] Blum, T. R.; Zhu, Y.; Nordeen, S. A.; Yoon, T. P. Angew. Chem., Int. Ed. 2014, 53, 11056

[17] Song, T.; Zhou, B.; Peng, G.W.; Zhang, Q.B.; Wu, L. Z.; Liu, Q.; Wang, Y. Chem.-Eur. J. 2014, 20, 678.

[18] Zhao, Y.; Huang, B.; Yang, C.; Li, B.; Xia, W. Synthesis 2015, 47, 2731.

[19] Wang, S.; Gates, B. D.; Swenton, J. S. J. Org. Chem. 1991, 56, 1979.

[20] Gates, B. D.; Dalidowicz, P.; Tebben, A.; Wang, S.; Swenton, J. S. J. Org. Chem. 1992, 57, 2135.

[21] (a) Bérard, D.; Jean, A.; Canesi, S. Tetrahedron Lett. 2007, 48, 8238 .

(b) Bérard, D.; Giroux, M. A.; Racicot, L.; Sabot, C.; Canesi, S. Tetrahedron 2008, 64, 7537.

(c) Bérard, D.; Racicot, L.; Sabot, C.; Canesi, S. Synlett 2008, 7, 1076.

(d) Sabot, C.; Bérard, D.; Canesi, S. Org. Lett. 2008, 10, 4629.

[22] Guérard, K. C.; Sabot, C.; Beaulieu, M. A.; Giroux, M. A.; Canesi, S. Tetrahedron 2010, 66, 5893.

[23] (a) Juha'sz, L.; Kürti, L.; Antus, S. J. Nat. Prod. 2000, 63, 866. (b) Wang, E.; Weinb, Y.; Kuo Y. Tetrahedron Lett. 2006, 47, 9195.

[24] Mohr, A. L.; Lombardo, V. M.; Arisco, T. M.; Morrow, G. W. Synth. 
Commun. 2009, 39, 3845.

[25] Dohi, T.; Nakae, T.; Toyoda, Y.; Koseki, D.; Kubo, H.; Kamitanaka, T.; Kita, Y. Heterocycles 2015, 90, 631.

[26] Chen, P. Y.; Wu, Y. H.; Hsu, M. H.; Wang, T. P.; Wang, E. C. Tetrahedron 2013, 69, 653.

[27] Alvey, L.; Prado, S.; Huteau, V.; Saint-Joanis, B.; Michel, S.; Koch, M.; Cole, S.T.; Tillequin, F.; Janin Y. L. Bioorg. Med. Chem. 2008, 16, 8264 .

[28] Shang, Y.; Qian, Y.; Liu, X.; Dai, F.; Shang, X.; Jia, W.; Liu, Q.; Fang, J.; Zhou, B. J. Org.Chem. 2009, 74, 5025.

[29] (a) Sako, M.; Hosokawa, H.; Ito, T.; Iinuma, M. J. Org. Chem. 2004, 69, 2598.

(b) Takaya, Y.; Terashima, K.; Ito, J.; He, Y. H.; Tateoka, M.; Yamaguchi, N.; Niwa, M. Tetrahedron 2005, 61, 10285.

(c) Bruschi, M.; Orlandi, M.; Rindone, B.; Rummakko, P.; Zoia, L. J. Phys. Org. Chem. 2006, 19, 592.

(d) Wang, G.; Wang, H.; Capretto, D. A.; Han, Q.; Hua, R.; Yang, S. Tetrahedron 2012, 68, 5216.

(e) Althagafy, H. S.; Meza-Aviña, M. E.; Oberlies, N. H.; Croatt, M. P. J. Org. Chem. 2013, 78, 7594.

(f) Magoulas, G. E.; Papaioannou, D. Molecules 2014, 19, 19769.

[30] Youn, S. W.; Eom, J. I. J. Org. Chem. 2006, 71, 6705.

[31] (a) El-Seedi, H. R.; Yamamura, S.; Nishiyama, S. Tetrahedron 2002, 58, 7485 .

(b) Kirste, A.; Schnakenburg, G.; Stecker, F.; Fischer, A.; Waldvo- gel, S. R. Angew. Chem., Int. Ed. 2010, 49, 971.

(c) El-Seedi, H. R.; Yamamura, S.; Nishiyama, S. Tetrahedron Lett. 2002, 43, 3301.

(d) Okada, Y.; Yshoka, T.; Koike, M.; Chiba, K. Tetrahedron Lett. 2011, 52, 4690.

(e) Chiba, K.; Fukuda, M.; Kim, S.; Kitano, Y.; Tada, M. J. Org. Chem. 1999, 64, 7654.

(f) Kim, S.; Noda, S.; Hayashi, K.; Chiba, K. Org. Lett. 2008, 10, 1827.

[32] Bhusainahalli, V. M.; Spatafora, C.; Chalal, M.; Vervandier-Fasseur, D.; Meunier, P.; Latruffe, N.; Tringali, C. Eur. J. Org. Chem. 2012, 5217.

[33] (a) Nascimento, I. R.; Lopes, L. M. X.; Davin, L. B.; Lewis, N. G. Tetrahedron 2000, 56, 9181.

(b) Pereira, A. C.; Magalhaes, L. G.; Goncalves, U. O.; Luz, P. P.; Moraes, A. C. G.; Rodrigues, V.; Da Matta Guedes, P. M.; Da Silva Filho, A. A.; Cunha, W. R.; Bastos, J. K.; Nanayakkara, N. P. D.; E Silva, M. L. Phytochemistry 2011, 72, 1424.

(c) Syrjänen, K.; Brunow, G. Tetrahedron 2001, 57, 365.

(d) Toshiyuki ,W.; Makoto, Nitta.; Kana, K.; Taketo, C.; Ye, Y.; Kuniro, T.; Toshiyuki, K.; Haruo, N.; Masaji, I.; Minako, K.; Yoshiaki, Y.; Yoshihide, S. Bioorg. Med. Chem. Lett. 2009, 19, 5905.

(e) Li, C.; Lu, J.; Xu, X.; Hu, R.; Pan, Y. Green Chem. 2012, 14, 328 .

(Cheng, F.) 